\title{
Omani English as a Foreign Language Teachers' Views about Participatory Professional Development
}

\author{
By Khadija Al Balushi
}

\begin{abstract}
This paper reports the findings of a study that develops a participatory model for TESOL teachers' continuous professional development (CPD) in Oman. This study used an action research methodology and data were collected using an online discussion group, semi-structured and focus group interviews with participant teachers. The findings indicated that the centralised top-down nature of the current CPD system seems to negatively affect the success of CPD in the in-service TESOL context in Oman. The evaluation of the participatory model of CPD adopted in this study showed that this model has a positive impact on participant teachers' CPD and three aspects of change were noticed: teachers' beliefs, their practices about CPD, and change in students (e.g., their reading habits). The data showed that the participatory model of CPD enabled teachers to make decisions regarding their CPD and encouraged them to play the role of critical reflective practitioners as well as preparing them as future transformative intellectuals.
\end{abstract}

Keywords: CPD, in-service courses, TESOL, teacher professional development, participatory professional development.

\section{Introduction}

Contemporary approaches to teacher professional development (hereafter PD) have evolved along with the paradigm shifts in teacher learning. Key shifts include a move away from transmission models of teachers' learning to more constructivist views that assume teacher-learners to be self-directed in their own professional learning and growth (Al-Balushi, 2017; Beach, 2017; Hung \& Yeh, 2013). Along the same line, there is a growing awareness of the potential of teachers' collaboration to encourage their learning (Vangrieken, Meredith, Packer, \& Kyndt, 2017; Al-Balushi, 2017; Reilly \& Literat, 2012). However, evidence from research done in Oman showed that teachers' continuous professional development (hereafter CPD) is currently imposed on teachers through in-service education and training of teachers (hereafter INSET) courses and workshops as well as other forms of CPD. Moreover, in-service TESOL teachers showed an interest in having a more active role in participating in their CPD process (Al-Lamki, 2009; AlYafaee, 2004). Given this, the general aim of this study is to examine Omani inservice TESOL teachers' CPD and to improve CPD in the in-service TESOL context in Oman through introducing a participatory model of CPD in Education to a group of TESOL teachers.

\footnotetext{
"Academic Programmes Senior Specialist, Ministry of Higher Education, Research and Innovation, Oman.
} 


\section{TESOL Teachers' CPD in Oman}

In the Omani context, a number of Omani researchers investigated the effectiveness of the CPD programmes offered by the Ministry of Education in Oman for in-service TESOL teachers. Al-Lamki (2009) used questionnaires and semi-structured interviews to investigate the beliefs and practices related to Omani TESOL teachers CPD. The study found that the CPD system adopted by the Ministry for TESOL teachers.is an important factor affecting the effectiveness of the CPD programmes offered to those teachers. The participant teachers in this study expressed their desire in playing a more active role in their CPD process. Yet, the CPD system is planned and delivered following a top-down approach in which teachers' involvement in making decisions regarding their CPD is limited. The results showed how such mismatch may negatively affect teachers' confidence and motivation towards CPD.

A number of other studies found some challenges and/or factors affecting TESOL teachers' CPD in Oman. Teachers' understanding and application of the CPD initiatives is found to be a significant factor as found by Al-Hakamani (2011). Other factors are TESOL teachers' overload of work, lack of time and lack of courage according to Al-Balushi (2012). Furthermore, the role of teachers previously held beliefs about teaching and learning affecting their benefit from the offered CPD activities was found to be another factor (Al-Balushi 2009; AlLamki, 2009). As well as that, studies have shown that English teachers' training needs are not fulfilled through the structured formal INSET training programmes offered to them (Al-Balushi, 2017). This could mean that the way CPD is offered to TESOL teachers in Oman and the models of CPD used in the Omani context might not fulfill those teachers CPD needs.

\section{Models of CPD}

Ingvarson (1998) used the term model in the context of staff development to refer to a design for learning which can embody some assumptions about where knowledge comes from in relation to teaching practice, and how a teacher acquires and/or extends his/her knowledge. He thinks that CPD models are specific processes and opportunities planned to help teachers develop professionally. Both Coldwell (2017) and Fraser (2005) state that CPD involves all activities teachers are engaged in to develop professionally. It includes a wide range of both formal and informal learning experiences which can vary from personal learning such as private reading to attending courses organised by local authorities. These CPD activities have different sources such as the school itself, school networks, and other external providers like local authorities, universities, colleges and private sector providers. Those providers have used different models of CPD overtime. For instance, in England, since 1988 the major educational reform initiatives were based on a technicist view of teaching assuming that change can be "delivered" in a linear way from the "centre" to teachers to implement it in their classrooms (Dadds, 2014, p. 9). Contemporary approaches to teacher CPD have, however, 
evolved along with the paradigm shifts in teacher learning from a transmission model of education that considers the role of teacher-learners are best seen as selfdirected as well as social learners. Thus, more emphasis is placed on engaging teachers in inquiry-based learning activities and/or collaborative learning such as building a learning community for professional development (Peercy \& Troyan, 2017).

Moreover, Sawyer (2001) determined that, over the years, the focus for PD initiatives has shifted from a deficit approach (focusing on content knowledge: use of external expertise); to a technical approach (focusing on teaching practice: school-based with outside help) to CPD (focusing on teacher professionalism and context: collaborative practice) (cited in Mushayikwa \& Lubben, 2009). The CPD provision; thus, has changed from external expertise to empowerment. By empowering teachers, professional developers are encouraging them to take the initiative in identifying and acting on their own individual needs. Broadly speaking, researchers over time have proposed a variety of models of CPD. For example, Kennedy (2005) examined a range of models of CPD (totally nine models) which he categorized into three main groups based on their purposes (i.e., transmission, transitional and transformative) as represented in Table 1 below.

Table 1. Spectrum of CPD Models

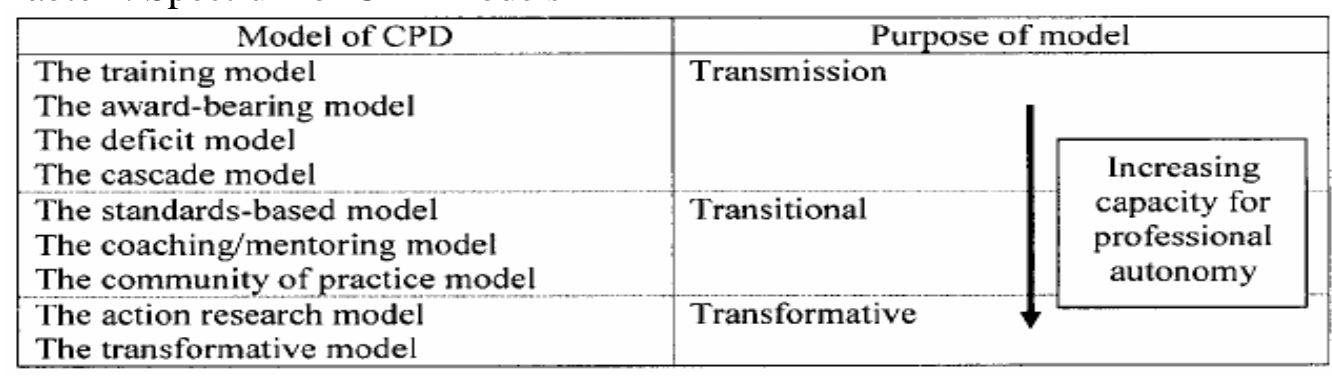

Source: Kennedy, 2005, p. 248.

1. Transmission models include: the training model, the award-bearing model, deficit model and the cascade model. CPD models which have a transmissive purpose rely on the development of teachers through externally delivered "expert" and focus on the technical aspects of the job rather than issues related to attitudes, values and beliefs (Fraser, Kennedy, Reid, \& Mckinney, 2007). This CPD type supports replication and arguably, compliance, but it does not support professional autonomy.

2. Transitional models include: standards-based models, coaching/mentoring models and a community of practice model. Within the transitional models, CPD supports either a transmissive or a transformative agenda, depending on its form and philosophy (Fraser, Kennedy, Reid, \& Mckinney, 2007; Kennedy, 2005).

3. Transformative models include the action research model and transformative "internalisation of concepts; reflection; construction of new knowledge and its application in different situations; and an awareness of the professional and political context" (Fraser, Kennedy, Reid, \& Mckinney, 2007, pp. 159-160). Thus, transformative CPD models have the capacity of supporting considerable professional autonomy at both the individual and the profession wide levels. Out 
of the nine models suggested by Kennedy (2005) only four are applied in the Omani CPD system: the training, the cascade, the coaching/mentoring and the action research models. However, the effectiveness of these models and the impact they have on teaching and learning in Omani schools was questioned by a number of researchers (Al-Balushi, 2012; Al-Hakamani, 2011; Al-Lamki, 2009; AlBalushi, 2009). For instance, Al-Balushi (2009) investigated the impact of an inservice training course on TESOL teachers' perceptions of and their classroom practices regarding teaching stories to young learners. The researcher found little changes in participants' perceptions and no noticeable change in their classroom practices when the course was over. Some of these studies also called for Omani teachers' active involvement in their CPD process (Al-Lamki, 2009).

\section{A Need for a Participatory Model of CPD in Oman}

Teachers' active involvement is increasingly recognized as a vital component of their CPD. However, in many EFL contexts, CPD is still largely built on the premise of knowledge consumption and knowledge transmission (Lee, 2011). This exactly applies to the Omani context where evidence from research has shown that English teachers' CPD is currently following a top-down approach (Al-Lamki, 2009). In other words, CPD is currently imposed on in-service TESOL teachers through INSET days and other forms of CPD. In response to such a gap in the EFL context generally and in Oman in particular, and also because Omani inservice TESOL teachers have showed an interest in having a more active role in their CPD process as Al-Lamki's (2009) and Al-Yafaee's (2004) studies concluded, the researcher has adopted a participatory approach to CPD in this study. This model provides a participatory learning environment that gives participants in a classroom or elsewhere the opportunity to become part of a professional community which helps them to explore abstract concepts in a nonthreatening social context, and then apply them in situations that hold personal relevance (Reilly \& Literat, 2012). Having said that, the participatory model of CPD designed for this study has some underpinning principles as shown in Figure 1.

Figure 1. The Underlying Principles for the Participatory Model of CPD

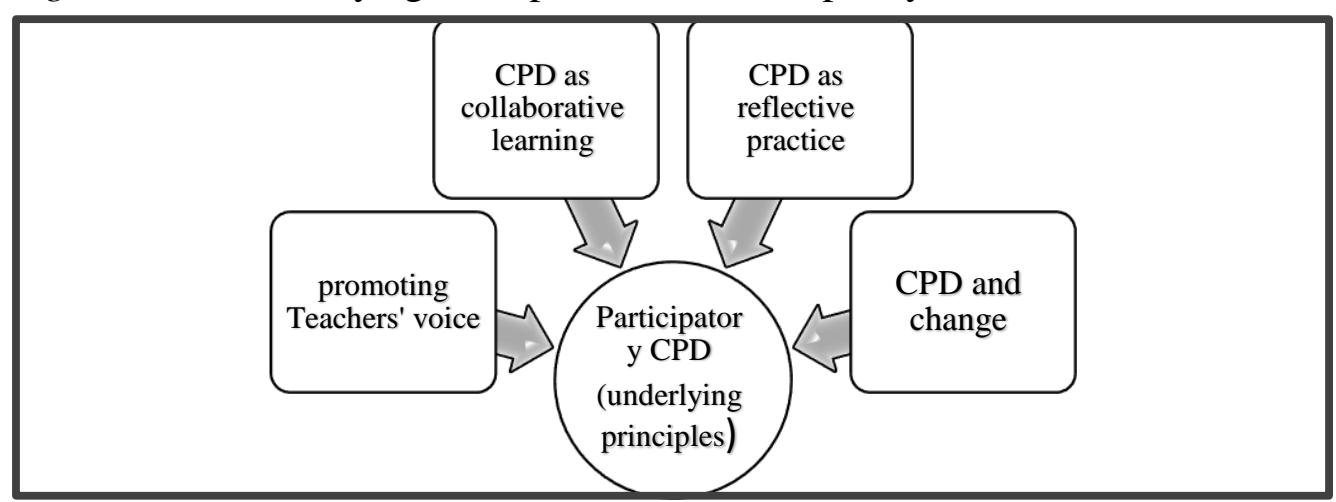

Source: Al Balushi, 2017. 


\section{Promoting Teachers' Voice}

Teacher participation in the education policy process helps to fulfil a core principle of deliberative democracy: "The normative legitimacy of a democratic decision depends on the degree to which those affected by it have been included in the decision-making processes and have had the opportunity to influence the outcomes" (Young, 2000 in Lefstein \& Perath, 2014, p. 34). This is significant because teachers are among those most responsible for carrying out the policies adopted, so their voices and their sense of ownership of policy is crucial to its effective implementation (Giroux, 2017; Bangs \& Frost, 2012). Relating this discourse to teachers' CPD, teachers' ownership of the CPD process is a condition for learning and change (Witte \& Jansen, 2016). Thus, there are a growing number of research studies in which teachers play an active role in developing teaching standards as part of their CPD (e.g., Oolbekkink-Marchand et al., 2017; Witte \& Jansen, 2016; Lefstein \& Perath, 2014). This study also focuses on promoting teachers' voices through the adoption of a participatory model of CPD. This model encourages teachers' active participation in their CPD process. For example, the design and delivery of some workshops during the action research phase of the study by themselves and the formation of a self-directed online discussion group focusing on self-selected topics. Hence, this model attempts to increase participant teachers' ownership, responsibility of their CPD and activate their voices.

\section{CPD as Collaborative Learning}

Collaboration can facilitate teachers' professional growth and development through supporting the development of teachers' skills and helping to sustain teachers' CPD in a more comprehensive manner (Kuusisaari, 2014; Day, 1999). This is because social support can help teachers to learn from one another, develop distributed expertise and support the construction of knowledge (Moran et al., 2017). Internationally, in countries such as Korea, Singapore, and Finland, teachers' professional collaboration with each other has supported teachers as they managed the challenges/complexities of teaching (Darling-Hammond, 2010). The participatory model of CPD adopted in this study focuses on professional collaboration to encourage and enhance teachers' CPD. This model is informed by the belief that learning happens through communication, social interaction, and reflection (Moran et al., 2017; Peercy \& Troyan, 2017; Vygotsky, 1978). Thus, in this study, opportunities for collaborative learning were provided across a partnership between teachers, SETs, and the researcher during the three workshops and in the online discussion sessions they participated in. This approach tries to break-down the Omani traditional assumptions about the hierarchical relationships among teacher trainers, regional supervisors, and teachers/SETs candidates through INSET and structural training. 


\section{CPD as Reflective Practice}

According to Schön (1987), it is important for teachers to reflect on experiences as they occur. Reflection means the process of engaging with learning and/or professional practice that provides an opportunity for the teacher to monitor, revise, critically analyse and evaluate their own practice continuously (Pollard et al., 2008). Reflection also both influences and is influenced by the processes involved in dialogical teaching and collaboration (Vrikki et al., 2017). As such, "reflection is not an end in itself, but rather a vehicle used in transforming raw experiences, which can ultimately serve the larger purpose of the moral growth of the individual and society" (Finefter-Rosenbluh, 2016, p. 2). The participatory model of CPD encourages teachers to be reflective practitioners where participants can critically reflect on their practices related to teaching and CPD, and the presentation of topics/ideas trying out such ideas at their schools and then in the online discussions were important ways in which this was achieved in this study. Such process of reflective practice supports the development and maintenance of professional expertise; thus it feeds a constructive spiral of PD and capability (Pollard et al., 2008). Given the nature of teaching, CPD and learning should never stop.

\section{CPD and Change}

Bubb and Earley (2007, p. 21) emphasise that effective CPD "is likely to consist of that which first and foremost enhances pupil outcomes, but which also helps to bring about changes in practice and improves teaching". Huberman (1995) demonstrates the cyclical nature of the change process for teachers: change in beliefs lead to change in practice that bring change in students' learning that bring further changes in practice that result in additional changes in belief and so on. The relationship between these processes is also reciprocal with change in one being contingent on changes in another (cited in Opfer, Pedder, \& Lavicza, 2011). However, change does not just result from a linear process flowing from CPD activity but is also influenced by cultural, structural, and political aspects of a teacher's experiential context (Opfer, Pedder, \& Lavicza, 2011). The adopted participatory model of CPD proposes change as being driven by personal beliefs, motivations, interests and social/historical contexts and processes rather than solely through rational and logical accumulation of skills and knowledge by participating in a learning activity. The model assumes that teachers bring their own beliefs, practices to their own learning or CPD experiences, and these have been taken into consideration in the workshops and online discussions. For teacher learning to occur, change may occur in beliefs, practices, and students or through any combination of these three areas of possible change. 


\section{Methodology}

\section{Ethical Considerations}

Ethical considerations are an important part of any research and several ethical issues can confront researchers (Punch, 2014). Therefore, at the beginning of this study, ethical approval was obtained from the Ministry of Education in Oman where this research was conducted to get permission for doing the study and obtain access to teachers and senior English teachers (the research participants), so to avoid any act of unethical behaviour. Moreover, assurances of confidentiality and anonymity were outlined within the framework of voluntary informed consent given to participants, and in the instructions accompanied with the interviews. Furthermore, participants' permission was granted to audio record the interviews before these went ahead. The researcher also used pseudonyms when presented the research findings in the study.

\section{Action Research}

There is an abundance of theoretical and practical literature on action research. For example, in critical action research in teacher education, Kincheloe (1991) recommended that the "critical teacher" exposes the assumptions of existing research orientations, critiques the knowledge base, and through these critiques reveals ideological effects on teachers, schools and the cultural view of education. According to Troudi (2015), in the fields of TESL and TEFL where the current study is located, Burns $(1999,2010)$ and Wallace (1998) offer a version of action research that is strongly aligned with the movement of teacher research and professional development (cited in Troudi, 2015). The action research adopted by the researcher in this study challenges teachers' beliefs about CPD and explores the ideological effects of the participatory model of CPD on teachers. Based on these effects, the study is aiming at a change and improvement in the CPD system in Oman through recommending this model to the Omani MOE. In order to achieve this aim, the research participants and the researcher designed and conducted three workshops and established an online discussion group; data were collected using different methods as could be seen in Figure 2.

The participants in this study were 18 in total: 15 teachers and 3 Senior English Teachers (SETs) from three schools in Oman (6 from each school). The action research included: 1) three workshops 2 hours each making a total of 6 hours; 2) an online discussion group for 6 weeks; and 3) doing a focus group interview with all research participants followed by 6 individual interviews to see participants' reaction to the participatory model of CPD. 
Figure 2. The Action Research Phase of the Study

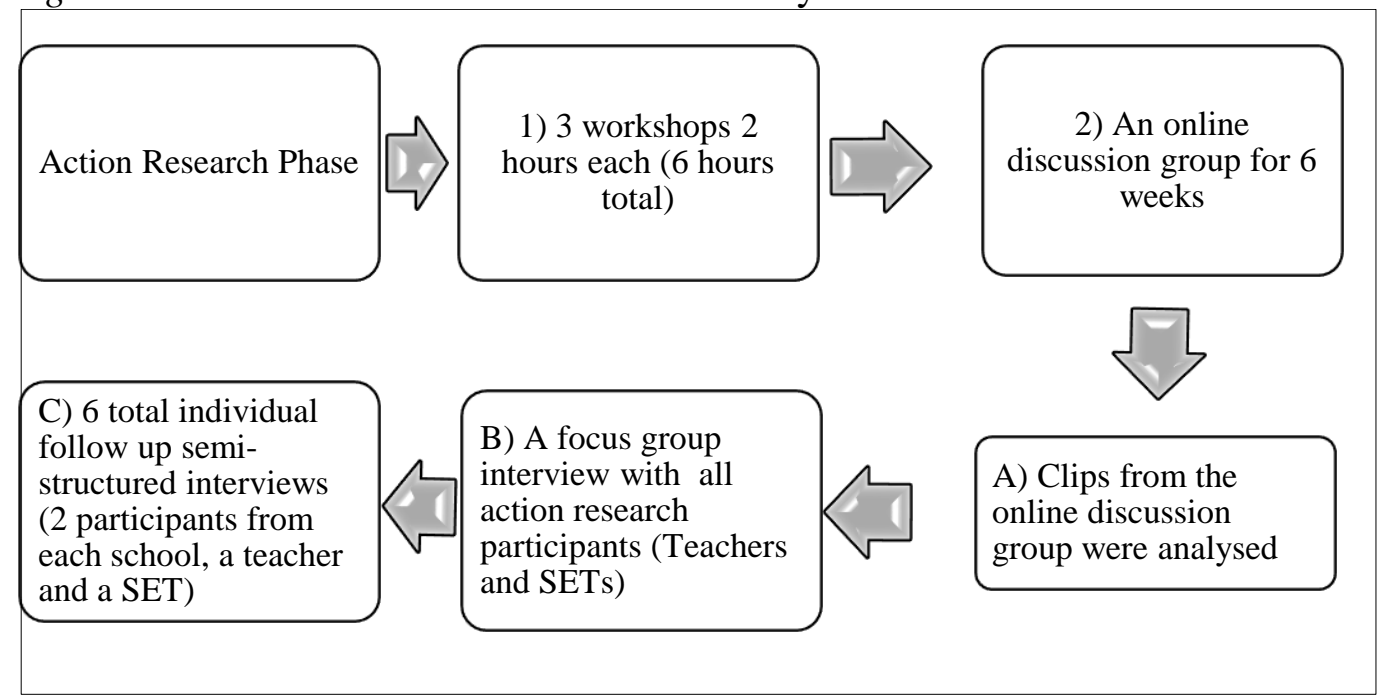

Source: Al Balushi, 2017.

\section{Three Workshops}

There were three workshops in total (2 hours each) which were carried out at one of the three schools and all participants attended the three workshops. These workshops focused on introducing participants to the participatory model of CPD. Participants actively participated in the workshops and completed all the activities. The researcher designed and delivered workshop (1), prepared the materials and delivered it. In this workshop, the researcher also asked participants to organise themselves into five different groups according to the five topics given to them for reading.

In workshop (2), participants planned about the topic they chose and agreed on the different times to present about their topic to whole group; explaining what this idea is and its importance for English teachers' CPD: Group (1) presented about activating "Practitioner-based activities" such as doing action research, reflection on teaching using journals, peer observation, team teaching. Group (2) discussed about activating "Communities of practice" in Oman between English teachers for their CPD such as online discussion groups, WhatsApp groups. Group (3) deliberated about 'Creating an intellectual atmosphere for intellectual debate' in which the idea of Omani English teachers as intellectuals was discussed and an example was given from choosing the Shura council "political representatives for different states in Oman" (an event that was taking place during the time of the workshops). Group (4) discussed about encouraging teachers to read "the centrality of reading as a culture" through which this group discussed the idea of "motivating teachers to read and making reading a daily habit for them to develop professionally". Group (5) looked at "the centrality of reading as a culture" (which focused on motivating students to read), and creating reading cultures in Omani schools. In workshop (3) each group discussed how their presented topic can be applied by English teachers in Oman, the challenges associated with it and how to overcome these challenges. 


\section{Online Discussion Group}

From the research participants, a teacher initiated establishing an online discussion group (WhatsApp group) and wrote a monthly timetable showing who will be responsible for leading the discussion every day during the month which was agreed to be rotated. The majority of the participants participated actively in the online discussions and reflected on issues discussed in the action research workshops, what they have learnt from these workshops, the ideas they applied in reality and any questions they have. The researcher noticed that their contributions in the online group were very beneficial, so the researcher used some clips from their discussion as a data and analysed them qualitatively.

\section{Interviews}

The focus group interview was done with all 18-research participants. This was followed by 6 individual semi-structured interviews to follow up the focus group interview data and dig deeply in participants' responses to know teachers' reaction to the participatory model of $\mathrm{CPD}$. The aim behind doing both semistructured and focus-group interviews was to follow up individual participants' ideas, and dig deeply into them by investigating feelings and motives (Punch, 2014; Bell, 2010; Kvale, 2009). An interview schedule was designed with introductory comments followed by a number of questions, follow-up prompts and probes. All questions, prompts and probes sought participants' views about the participatory model of CPD adopted by the researcher. After collecting all data, it was analysed qualitatively which involves preparing and organizing the data for analysis, exploring the data then reducing it into themes through a coding process, and finally representing the data in figures, tables or a discussion (Jamieson, 2016; Creswell \& Plano Clark, 2011; Creswell, 2007).

\section{Results}

\section{Teachers' Reaction to the Model}

Workshops-Positive Experience. The results of individual interviews with participating teachers indicate that participating in the workshops was a positive experience for many participants (11 out of the 15 teachers stated that). This was echoed by two third of the participants in the focus group interview where they indicated that they liked the experience of joining in the three workshops, and they felt that their awareness about the workshops content had been enlightened. By the same token, all of the SETs reacted positively to the workshops in follow-up semistructured interviews undertaken with them. For instance, the three SETs commented that all their teachers liked the workshops and they were always talking positively about the ideas presented in these workshops. I think that the participatory nature of these workshops seems to positively affect teachers' beliefs about CPD as they participated with others to learn and be updated. In other 
words, it was a participatory learning context where thinking was made visible through networking with others; learning was not an individual task for the individual mind, but an exploration within a learning community (groups of teachers working together in these workshops), which provided a rich, robust learning experience for all participants (Reilly \& Literat, 2012).

In the following extract, Laila (a SET) explains how actively and collaboratively they participated in these workshops:

\begin{abstract}
"When we divided the topics in the workshops between us as groups...the first thing we did after knowing our topic is taking the reading article related to this topic, and dividing it between us as a group of teachers without differentiating between SETs and teachers (each one was responsible for reading part of the article) and I got my part like the other colleagues, each one read her part and we discussed about the whole topic and how we are going to present it to all teachers in the coming workshop, in the workshop the whole team presented our topic together where each of us talked about her bit and then we all concluded by suggesting some ways of applying this idea in our schools and with our students".
\end{abstract}

Consequently, the findings reveal that participating in the three workshops was a positive experience for the participants in that it positively affected their beliefs about the importance of CPD. The participatory nature of the workshops related to being actively involved in their learning process was valued by respondents. Such result resembles the findings of other studies (e.g., Borg \& AlBusaidi, 2012; Lee, 2011). Thus, many participants agreed that the workshops were inspiring and added a lot to them. For example, Anisa (a teacher) emphasizes:

"Personally I liked these workshops a lot and I hope that I always join such types of workshops that are inspiring and enriches our knowledge with new ideas and information, I liked all the workshops, honestly I have now 8 years of experience of teaching and I joined many workshops but I never met such workshops, it was really inspiring for me and I loved all the ideas discussed and the online group".

Online Discussion Group-Useful Contributions. Participants were asked for their views of the overall value of the online discussion groups as well as their views on the contributions of different group members and whether these added anything to them. The results indicated that participating in the online discussion group was a useful experience for the majority of respondents and that participants' contributions in this group were also seen as useful. This is because, these contributions were based on practicing teachers' real experiences as the data shows. For example, Halima remarks:

"(colleagues)...were contributing greatly and their ideas were really much appreciated because they were from their experience".

Moreover, all respondents agreed that the discussed issues were useful because they were of concern for everyone in the group as Huda notes:

"...the ideas that we discussed were concerning all of us, even all teachers I think". 
The data also shows that participants' contributions in this group were fruitful because they suggested practical ways that other teachers could benefit from. For example, Huda explained that she benefited from the idea of creating a reading culture that was discussed in the online discussion. As she said:

"Ya for me they discussed how they applied creating a reading culture in their schools and I benefited from their ideas and used some of these ideas".

Lulwa further liked the discussion on student discipline, as she said:

"...the ideas they discussed were really beneficial especially the ideas about punishing students for me was really beneficial and it added to me how others deal with the same issue".

\section{Teachers' Learning from the Model}

New Ideas from Shared Experiences. The data demonstrates that participating in the three workshops and in the online discussion group helped participants to learn new knowledge and ideas from their colleagues shared experiences. It shows that co-learning happened in these events where the participant teachers pooled their skills and knowledge, and shared them in the tasks of teaching and learning (Reilly \& Literat, 2012).

For example, Badriya mentions the benefit she got from joining the workshops:

"... I feel that others ideas enrich my knowledge and honestly this workshop added a lot to me personally and gave me new ideas".

Regarding the online discussion group, Alya referred to the benefit she took from joining this, saying:

"Exchanging experience is very good and it shows us solutions to some problems we are facing where our colleagues in the online discussion group discussed issues that we are concerned about, also we ask them about their experience of some teaching methods they applied and felt were good..."

The above quote suggests that participants have shared experiences with each other during the online discussions and got to know some ideas from each other and that these ideas were directly related to their teaching and classroom practice.

This finding corresponds with Appleby and Pilkington's (2014, p. 48) model of critical professional development which supports the role of dialogue and discourse for professional learning. In fact, the workshops and the online discussions involved dialogue with peers and groups about different aspects of teaching, learning and the professional development of teachers. Moreover, participants' reflected on these professional exchanges and experiences which possibly enabled more rigorous and focussed learning and meaning making activity to take place (Vrikki et al., 2017). 
Participating in Communities of Practice. The data revealed that the participatory model of CPD has added a lot to the participants since they were joining a professional community of practice (the researcher, teachers and SETs from different schools as well as their colleagues) through which they discussed issues, shared concerns and learned from each other's' ideas and contributions. For example, Farida explains that:

"The idea of communities of practice that we discussed in the workshops was a great idea, it showed me how easy it can be that when we face any problem we can find solutions for it by discussing and communicating with others, asking colleagues for their experiences and so on".

Moreover, Figure 3, from one of the online discussions in the group, provides an example of how Huda shared her experience of a book that she read, and how her colleagues discussed the ideas presented in the book to help children with their reading; thereby demonstrating the benefits of creating a community of practice for participants.

Figure 3. Participants' Sharing Experience of Reading Books

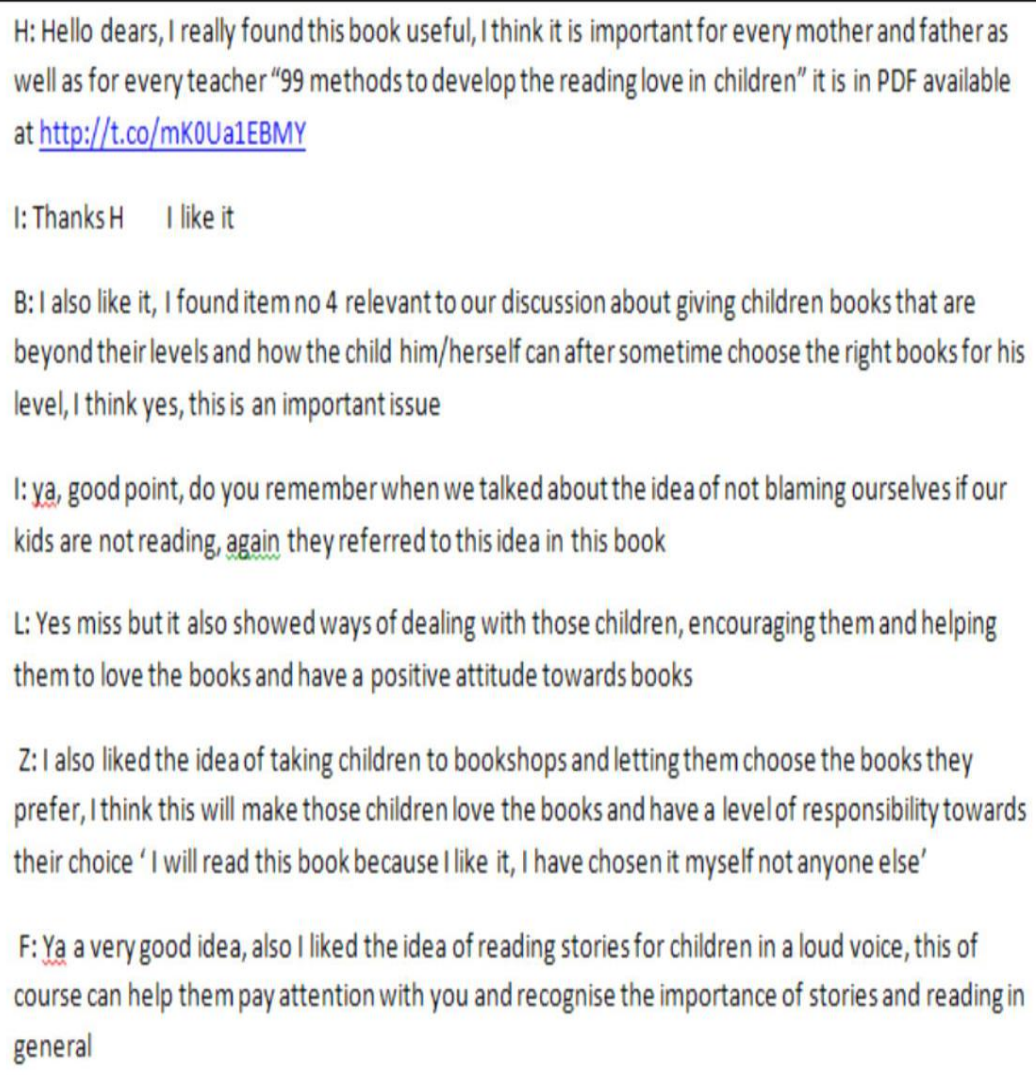

As could be seen in Figure 3, participants are demonstrating an online community of practice as practitioner teachers are sharing their experience of a book they read and relating this discussion to previous discussions they had about the same topic (e.g., giving children books that are beyond their level and not 
blaming themselves that students are not reading....etc.). They followed up the discussion to specific ideas presented in the book they read (e.g. encouraging students to read, reading stories for children in a loud voice...etc). This is an example of a real community of practice where teachers are sharing experience and building on each other's ideas to benefit and learn from each other.

Research and Reflection Skills. The data shows that participants have gained some skills as a result of joining the participatory model of CPD. Researching is one of these skills which some participants referred to. I think that this might be the result of the awareness-raising activities that were included in the workshop about the importance of research for teachers and carrying out action research. The literature has well documented that many teachers rarely engage in research unless encouraged to do so (Borg, 2009 in Wyatt, 2011). Thus, some teachers indicated in the follow-up individual interviews that they are planning to do action research after they joined the workshops. For example, Amal illuminates that:

"...participating in these workshops helped me get new ideas, read in some topics and remind myself of the information I already have about action research especially and how can we do action research in reality, for example, I thought of doing an action research about the challenges teachers face in shared writing lessons".

In addition, the data shows that respondents have gained some reflection skills as they reflected on the ideas they discussed in the workshops and online discussion group. This is what Schön (1987) called reflection-on-action which takes place after the event and is a more deliberative and conscious process. This type of reflection involves looking back at an event (in this case after joining the workshops and online discussion group) it is a form of retrospective reflection (Schön, 1987). Alya expresses that:

"...also inside the school sometimes we reflect on the ideas we discussed in the online discussion group".

From my viewpoint, both research and reflection skills that participants stated they have gained after joining the participatory model of CPD seem to help participants to critically reflect on their practice. Through such critical reflection on practice, they should then be able not only to examine the technical aspects of their teaching, but also to look critically at issues, both within the school as a whole, and outside which might have impacts on the quality of teaching and learning in the classroom (Harrison, 2011). Therefore, these skills are crucial for teachers' CPD which can help them explore more critically the underlying assumptions in their teaching practices, then to build their understanding of teaching and learning and add to their professional knowledge (Harrison, 2011; Pollard et al., 2008).

Participating in Debates. During the second workshop which was led by the participants, one group of teachers (group 3) discussed the idea of Omani English teachers as intellectuals and the need to create an atmosphere for intellectual debate in Omani schools. Participants provided an example of that from an event that was taking place during the time of the workshops (October 2015) which was 
elections for the Shura council representatives (political representatives for the different governorates in Oman). This group intelligently showed participants how teachers in Oman can participate in intellectual debates like choosing the appropriate people to be the representatives of their states at the Shura council. They added that currently many people in different states in Oman are choosing their representatives according to family relationships or to cultural and social considerations. They railed against that arguing that teachers need to have an enlightening role in this regard by discussing such issues at their schools and even taking these ideas to their society by talking to their family members and the public people about choosing the best people to be their representatives at the Shura council. They stated that through participating in such types of intellectual debates or any other educational debates teachers can learn and develop professionally.

An example of participants' engagement in educational debates was present in the online discussion strings where teachers' agreement and disagreement with each other was clearly evident. I think such types of discourse are important in that they provide teachers with the chance to organize collectively to improve the conditions under which they work (Giroux, 2013). Figure 4, from one of the online discussions, shows participants' beliefs regarding punishment.

Figure 4. Participants' Beliefs Regarding Punishment

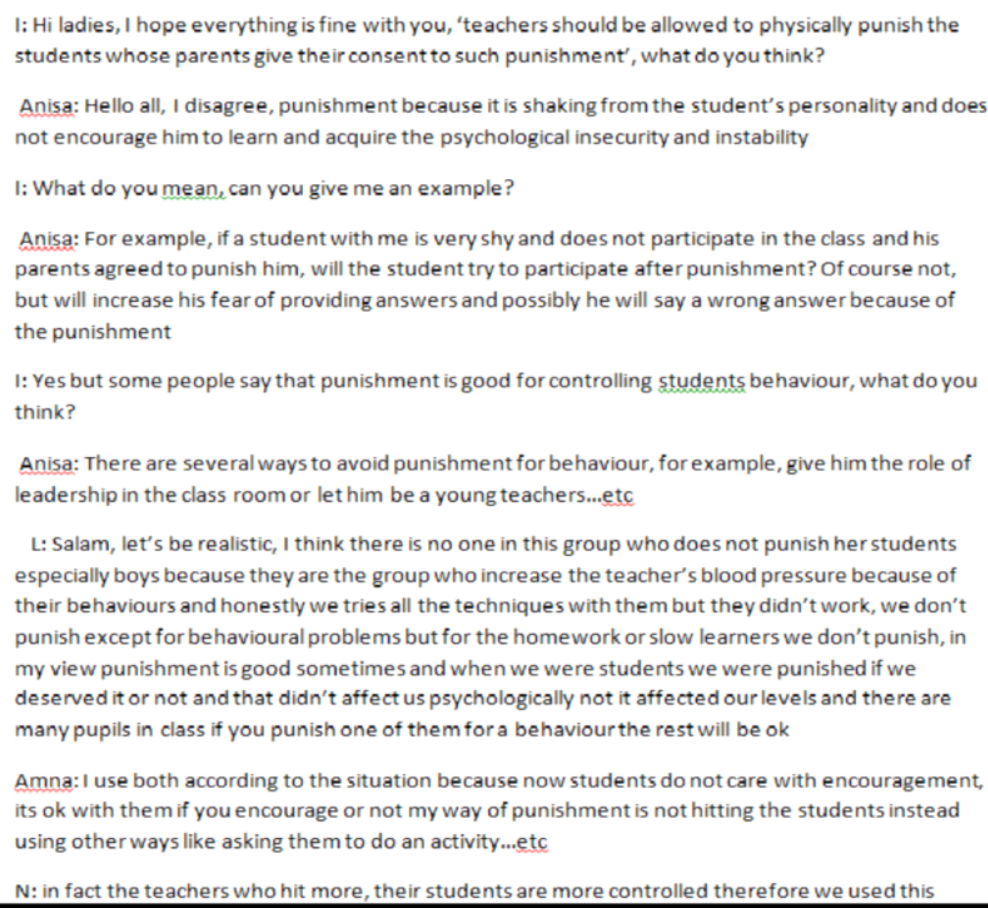

Figure 4 represents participants' ideas and beliefs about punishment of students. The debate among participants who are with or against the topic shows how each participant is trying to justify his/her idea (e.g., those who are against punishment of students show how punishment can affect students' personality negatively...etc., while those who are with punishment gives justifications for 
classroom control...etc.). It seems that participating in such intellectual debates is an example of healthy discussions among teachers where they are discussing issues of concern, justifying their ideas and learning from each other's ideas and views, which can positively contribute to their professional development.

\section{Views about Impact on Practice}

Creating a Reading Culture in Omani Schools. The data from individual and focus group interviews as well as online posts shows that participants claim to have used some of the ideas from the workshops and online discussion group in practice. A key idea that almost all participants said that they used regarding developing themselves professionally is reading. Many respondents (16 out of the 18) stated that they developed a love to read after participating in the workshops. Halima, for instance, clearly states that "I also benefited from the reading, I myself started to read now after talking about it in the workshops, and I started loving to read". The majority of participants also remarked that reading has become a habit for them as Laila for example states:

"...for ourselves now at least we specified a time for reading".

Furthermore, the data shows that respondents tried to create a reading culture in their schools by encouraging their students to read as this was repeatedly reported by some participants. Moreover, the three SETs said that the majority of their teachers have applied this idea with their students. For example, Laila (a SET) explains the process through which they applied this idea in their school:

"we started with our students by advising them on the importance of reading, then we provided them with story books and other books to read, we also encouraged our learners to borrow books and that each child finishes reading 7 books will be rewarded".

In Figure 5 (from one of the online discussions) Huda shares with her colleagues how she used the reading idea with her pupils to encourage them to read and the process she followed regarding that.

In this example, Huda showed her colleagues the different steps she followed to create a reading culture in her classroom by encouraging her students to read (e.g., by asking each student to buy a book, keeping reading records...etc.). The specific steps that she shared with her colleagues represent how this participant teacher has benefitted from the workshops and the ideas presented in them through creating a reading culture in her classroom. This also might show how online discussion can be a good way of sharing experience, learning from each other and developing professionally, as other teachers might be benefitted from the process followed by Huda to encourage her students to read. 
Figure 5. A Participant's Experience of Encouraging her Students to Read

$\mathrm{H}$ : Hi all, how are vou doing I have applied the idea of encouraging my students to read, I asked every child to buy a new story book that he/she can read, very simple and not expensive, every single child bought a story, they wrote their names on their stories and started reading their own stories, once each child finished reading his/her story, his parents wrote notes that the story was read by the child and then he brought it to class marked with his name, and all students put their stories in a box, then I asked each child to choose another story, take it home to read it and so on, here is the samples I used for that, the first form is a letter for parents explaining our reading project and what is expected from a child, this form also asks parents to buy stories for their children according to their levels and interests, I also emphasized that if any parent cannot buy just let me know and I will provide their kids with suitable stories (as below)

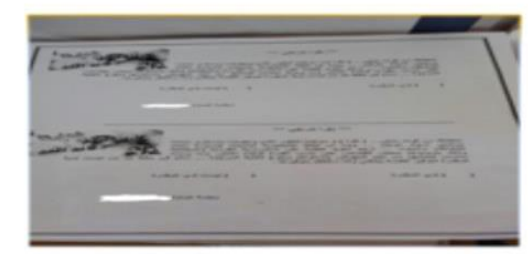

$\mathrm{H}$ : I also attached to each child's book a reading record where each child's parent can write the title of the story the child has read, date, whether the story was finished or not and the child's general impression about the story he/she has read (like this)

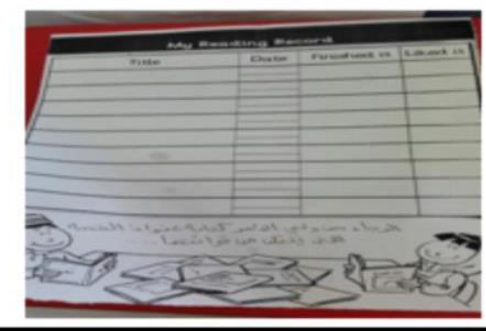

Teachers' Views about Impact on Students. The data from the individual and focus group interviews indicates that some of the ideas presented in the workshops and in the online discussion group have positively impacted on students' attitudes towards reading. Some participants ( 7 in total) claimed that many students in their classes are now more eager to read. In the following quote Anisa for example confirms that:

"some of my pupils only during this month read 18 stories and are still searching in their ipads for other stories to read instead of playing games in their ipads as they were doing before, their attitudes towards reading changed positively and now they love to read, and tomorrow I will reward my students those who read the biggest numbers of stories".

Kane and Warner (1997) stressed that the climate in which reading takes place becomes one of the most influential aspects of a child's motivation to read. There are some suggestions from the data that students' positive attitudes towards reading and the desire to read is a result of their positive reading experiences at school but more follow up research, outside the scope of this study, is needed to establish how far the participatory model has led to changes in student learning. 


\section{Constraints of the Participatory Model of CPD}

The findings indicate that a number of things might prevent teachers engaging in a participatory model of CPD. These would need to be addressed if a participatory model of CPD is to be successfully introduced in Oman. The first constraint as the data has shown is time, the majority of interview respondents (16 in total) claim that they have no time for participating in such events as online group discussions and indeed not many respondents were active in these. When asked for the reasons behind that, they complained that time was a real challenge for them which stopped them from participating in some of the online discussions although they believe that if they had contributed more to discussions this would have made them more fruitful. For example, Badriya states that:

"...usually they were discussing in times not suitable to me so I usually missed their discussions but honestly I always read what they write in that group, the different discussions and ideas before I sleep, I love to read others ideas to benefit from them even if I missed the discussion, these groups are really good but sometimes unfortunately due to some reasons not everyone can be present at the same time".

Anisa suggested that this challenge could be overcome through pre-planning on the part of participants and agreed commitment to participate between different participants. As she said:

"The disadvantages especially for the online discussion group might be that not all can be free and online at the same time to discuss issues but by pre-planning and agreement I feel there will be no disadvantages with such ideas and models".

The second constraint as shown by the data is workload which was reported by all focus group and individual follow-up interview respondents as a key restriction impacting on their engagement with the participatory model of CPD. Some participants stated that such a participatory model adds more work and is an extra burden on teachers. Huda for example highlighted the challenge of undertaking classroom research:

"...especially when we talk about the students reading project, you have to follow up students and even if you want to let them do it by themselves they come to you teacher I have read this and they need some attention from you and also we have to follow them from time to time which is more work added to us".

Nevertheless, the data shows that if teachers' workload is reduced then they can join the participatory model of CPD and develop professionally as Salima contends:

"...but before applying such a strategy or others the Ministry should think seriously of reducing the workload on teachers, we want to do lots of things, we want to develop professionally, we want to change but with all the school responsibilities and home it is really difficult, I hope the Ministry will apply this participatory model but after 
reducing the workload on teachers because at the end we are human beings and we want to work and improve but also we need sometimes to have a rest".

The third constraint with the participatory model of CPD as participants noted is teachers' personality. The data indicates that some teachers are keen to develop themselves professionally while others are not. Karima (one of the SETs) gives an example in this respect from her own teachers, she articulates:

"For example, from my school 5 teachers joined the workshops, 4 of them I can tell that really tried to benefit from the ideas presented in the workshop but 1 of them no, she only attended and she is not only like that in these workshops we did with you miss or in relation to this topic, but this is her personality".

\section{Discussion and Recommendations}

The data revealed that EFL teachers in Oman experience different CPD opportunities (e.g., INSET courses, cascading INSET, coaching and mentoring). All of these opportunities seem to be organised and/or funded by the MOE in Oman. However, findings from previous studies in Oman showed that many of these CPD opportunities failed to meet EFL teachers' needs (Al-Balushi, 2017). It seems that the MOE in Oman is not following a systematic way in collecting, analysing and assessing EFL teachers' needs in Oman in order to meet these needs. Moreover, some Omani researchers questioned the effectiveness of INSET courses in contributing to changes in EFL teachers' beliefs and/or their classroom practices (e.g. Al-Balushi, 2009; Al-Lamki, 2009). This is because most of the CPD opportunities offered to teachers follow transmission approaches/models of teachers' learning because "they seek to transmit a set of predetermined, preselected, and pre-sequenced bodies of knowledge" from teacher educators to teachers (Kumaravadivelu, 2012, p. 8).

In order to help teachers develop the capacity to address their classroom realities and to evolve as professionals there is a need for alternative posttransmission approaches to helping teachers learn and develop professionally. In this regard, Al-Balushi (2017) recommended that there is a real need for more dialogic and collaborative forms of CPD in Oman. Therefore, the current study adopted a participatory model of CPD and investigated its effectiveness in the Omani EFL context.

Introducing the research participants to the participatory model of CPD, the findings reveal that participants were in favour of this model. This is due to the post-transmission perspective underlying this model which seeks to restructure teachers' CPD so that it transcends the limitations of transmission models (Taylor, 2017; Kumaravadivelu, 2012).The critical participatory nature of this model also paid attention to broader historical, political, social, cultural and educational factors that impact teaching and the CPD of teachers in Oman (Moran et al., 2017). It helped participants to make decisions regarding their CPD, to play the role of reflective practitioners and possibly help them become transformative intellectuals. 


\section{Teachers as Decision Makers and Reform Agents}

The findings from the current study revealed that the participatory model of CPD enabled teachers to make decisions regarding their CPD and be the "agents" of their own professional development. This is because they were involved in their CPD process and have decided by themselves the content of workshops 2 and 3 . They also decided the topics they wanted to discuss in the online discussion group and led these discussions by themselves. Such findings are significant because a new discourse circulating about teacher professionalism is that of 'democratic professionalism' which seeks to "demystify professional work and build alliances between teachers and excluded constituencies of students and members of the community on whose behalf decisions have traditionally been made either by professions or by the state" (Apple, 1996 in Day \& Sachs, 2004, p. 7). The core of "democratic professionalism" is the emphasis on collaboration and cooperative actions between teachers and other educational stake holders. It suggests that the teacher has a wider responsibility than the single classroom and this includes contributing to his/her school, the system in general, other students not only the ones he/she is teaching, the wider community and collective responsibilities of teachers themselves as a group and the broader profession (Brennan, 1996 in Day \& Sachs, 2004).

However, teachers are often "marginalized" in the policy-making process and sufficient consultation is often absent in relation to their CPD (Wong, 1995, in Wai Yan, 2011). The effectiveness of such a kind of 'bureaucratic-managerial approach' to teacher CPD policy is under doubt (Vonk, 1991 in Wai Yan, 2011). This marginalization of teachers raises the myth of teacher professionalism, in which teachers' professional status has been neglected in the policy formulation process. In fact, nowadays educational researchers call for teachers' voice and their active participation in CPD process. For example, Bangs and Frost (2012) accentuated that it is time to consider approaches to teacher and school development that puts the teacher at the centre of the process if we want them to influence both policy and practice. This could explain participants' positive reaction to the participatory model of CPD as they felt that their voice is heard though their CPD participation. For example, Anisa states:

"I feel I have an opinion within the community and give my justifications for my opinion ... The advantages as I said are increasing teachers' self-confidence and they feel that they have a voice and their voice is heard"

\section{Teachers as Reflective Practitioners}

The findings from this study revealed that teachers have learnt some skills from being part of the participatory model of CPD. Becoming aware of the importance of researching their own practice and reflecting on what they are doing are some skills that respondents probably have gained from participating in the workshops and online discussion groups. This means that the participatory model has helped participants to critically reflect on their practice and become reflective practitioners. Yet, such practices are not well activated in the current CPD system 
in Oman as some previous studies have shown. For example, Al-Zedjali (2004) investigated teachers' reflective practices and fostering professional development through post-lesson discussion. She looked at the perceptions of EFL teachers and supervisors. This study found that the concepts of reflection and teacher autonomy are encouraged in theory but they are absent in practice in Oman.

In the ELT literature, Richards and Lockhart (1996) discussed the idea of critical reflection and how it can trigger a deeper understanding of teaching because it involves examining teaching experiences as a basis for evaluation and decision making as a source for change. In other words, critical reflection involves posing questions about how and why things are the way they are, what value systems they represent, what alternatives might be available, and what the limitations are of doing things one way as opposed to another. They added that teachers who are involved in critical reflection are better able to evaluate their stages of professional growth and what aspects of their teaching they need to change. When such reflection is done routinely, it enables teachers to feel more confident in trying different options and assessing their effects on their teaching.

Throughout the action research part of this study, I think that the research participants were exposed to Richards and Lockhart's (1996) idea of critical reflection through an experiential learning cycle. This is because they discussed some issues in the three workshops and applied some of these ideas practically such as creating a reading culture in their schools among teachers and students. Participants further reflected on this in the online discussion sessions and then went back to their schools to make changes to the ways of administering such reading culture according to their colleagues' ideas in the group. Experiential learning also acknowledges that much informal learning takes place outside formal educational settings. This is true for this research participants as the results show that after participating in the three workshops and online discussion sessions, participants started initiating establishing smaller groups according to their interests/needs and working collaboratively in these groups to discuss issues of concern. For instance, grade 1 teachers created a group to reflect on ideas discussed in the workshops and online discussion sessions in relation to teaching grade 1 . In this way reflective practice allowed those participant teachers to make sense of all learning opportunities available to them, both formal and informal, and to recognise and evaluate it when they talked about the benefits and constraints of the participatory model of CPD and the activities they were engaged in.

\section{Teachers as Transformative Intellectuals}

The findings show that the participatory model of CPD encouraged teachers to participate in debates and discuss the idea of preparing teachers as intellectuals in Omani schools which could possibly contribute to their CPD. This seems to be a crucial step in the Omani centralised top-down context whether regarding teachers' CPD or education in general. This is because teachers have a significant role in society and education. Teachers are one of the most significant resources a nation has for providing the values, knowledge and skills that prepare young people for productive citizenship but even more than that to give sanctuary for 
their aspirations and dreams for a future of hope, dignity and justice (Giroux, 2013, p. 458).

However, in many countries including Arab countries and Oman, one of major threats facing prospective and existing teachers is the increasing adoption of corporate and instrumental ideologies which emphasise technocratic and productoriented approaches to both teacher education and classroom pedagogy (Kershaw, 2012; Hargreaves, 2003). In this view, teaching is reduced to a set of skills and strategies and it becomes synonymous with methods or techniques. Hence, instead of learning to raise questions about the principles underlying different classroom methods, theories of education and research techniques, teachers are often preoccupied with mastering the best way to teach a given body of knowledge. Yet, this retrograde view ignores any understanding of pedagogy as a moral and political practice which can function as a deliberate attempt to influence how and what knowledge, values, and identities are produced with particular sets of classroom social relations (Giroux, 2013, p. 461).

The use of such technocratic and product-oriented approaches seems to represent forms of education that are based on the concept of "business/banking model of education" (Freire, 1970). In this view, education is seen as a process of depositing knowledge into others where knowledge is a gift bestowed by those who consider themselves knowledgeable upon those whom they consider to know nothing as Freire noted. He railed against this and argued that banking classrooms are mechanical rather than creative, and the transmission of knowledge through teacher monologues silences students' voices and discounts their personal backgrounds and experiences. As the "banking model" of education has generated and continues to generate greater and greater failure (Freire, 1998), there are more calls for post-transmission perspectives of education which anticipate teachers to play the role of transformative intellectuals who strive not only for academic advancement but also for personal transformation, both for themselves and for their learners (Kumaravadivelu, 2012).

To sum up, the findings from this study reveal that the participatory model of CPD can prepare teachers as transformative intellectuals. In the Omani context, a starting point to interrogate the social function of teachers as public and transformative intellectuals is to view schools as social, cultural, and economic sites that are inextricably tied to issues of control, power, and politics (Giroux, 2017 ; 2013; 1988). In other words, schools should do more than pass on a common set of knowledge and values in an objective fashion. In contrast, schools should be places that represent forms of social relations, language practices, knowledge and values that are particular selections and exclusions from the wider culture (Hargreaves, 2003; Pai, 1990). In such schools, the impact of teaching extends beyond the classroom to the community, the country and even the world.

\section{Benefits of the Participatory Model of CPD}

The current research has shown that the participatory model of CPD has benefits for teaches and the wider society in Oman. This is because there is a growing realization to make a meaningful shift in teachers' CPD from transmission 
models of education that consider the role of teacher-learners as passive knowledge-absorbers to more constructivist views of education that assumes teacher-learners to be self-directed in their own professional learning and growth (Beach, 2017; Kumaravadivelu, 2012). The current study practically and actively engaged a group of EFL teachers from different schools in Oman in the participatory model of CPD. The design of this model is based on socioconstructivist paradigms of teachers' learning where teachers were constructing knowledge of their own when engaged in CPD activities that were part of the participatory model (e.g., the three workshops) and in social discourse (onlinediscussions) that collaboratively took place during the action research phase of the study. As an example, the online discussion group that is established as part of the participatory model of CPD for teachers is an example of a professional community of practice where participants shared ideas and learnt from each other not only for themselves but shared these ideas with their colleagues at their schools as the data earlier showed. This study further utilized the technological revolution and the new generations' love of social media through the use of online chats between participants for their PD. Hence, the study provides practical suggestions on how to form both virtual and face-to-face communities of practice in Omani schools to share ideas and learn from each other.

\section{Conclusion}

The current study investigated Omani English as a foreign language teachers' views about participatory professional development; a model developed by the researcher to involve teachers in their CPD process. The findings showed that this model has a positive impact on participant teachers' beliefs about CPD, and their CPD practices. The findings also revealed that the participatory model of CPD enabled teachers to make decisions regarding their CPD and encouraged them to play the role of critical reflective practitioners as well as preparing them as future transformative intellectuals. Therefore, the study recommends the use of such participatory professional development forms in the TESOL context in Oman to contribute to teachers' learning and development.

\section{References}

Al Balushi. K. (2017). “...they feel that they have a voice and their voice is heard”: Towards Participatory Forms of Teachers' CPD in Oman (PhD Thesis). University of Exeter, UK

AL-Balushi, K. (2009). The impact of an INSET course on teachers' views and reported practices in teaching stories to young learners. In M. Wyatt \& J. Atkins (Eds.), Research Perspectives on Education in Oman. (pp.61-74). Sultanate of Oman: Ministry of Education.

AL-Balushi, K. (2012). Why are teachers reluctant for professional development? In N. McBeath \& N. Al-Kalbani (Eds.), Quality in ELT: Raising Pedagogical Standards (pp.87-97-ELT Conference proceedings). Muscat: SQU. 
AL-Hakamani, F. (2011). Investigating the Collaborative Professional Practices of Omani EFL Teachers and Their Relation to the Quality of Their reflection (MA Dissertation). Sultan Qaboos University, Muscat.

AL-Lamki, N. (2009). The Beliefs and Practices Related to Continuous Professional Development of Teachers of English in Oman (PhD thesis). University of Leeds, United Kingdom.

AL-Yafaee, M. (2004). An Investigation into the Attitudes of Omani Teachers to INSET Courses (MA Dissertation). University of Leeds, UK.

AL-Zedjali, F. (2004). Fostering Professional Development in Post Lesson Discussions: Perceptions of teachers and supervisors (MA Dissertation). University of Leeds, UK.

Appleby, Y., \& Pilkington, R. (2014). Developing Critical Professional Practice in Education. UK: Niace promoting adult learning.

Bangs, J., \& Frost, D. (2012). Teacher self-efficacy, voice and leadership: Towards a policy framework for education international. Brussels: Education International.

Beach, P. (2017). Self-directed online learning: A theoretical model for understanding elementary teachers' online learning experiences. Teaching and Teacher Education, 61, 60-72.

Bell, J. (2010). Doing Your Research Project: A guide for first time researchers in education, health and social science. (5th Ed.). England: Open University Press.

Borg, S., \& Al-Busaidi, S. (2012). Teachers' beliefs and practices regarding learner autonomy. ELT Journal, 66(3), 283-292.

Bubb, S., \& Earley, P. (2007). Leading and Managing Continuing Professional Development (2nd Ed.). London: Paul Chapman.

Coldwell, M. (2017). Exploring the influence of professional development on teacher careers: A path model approach. Teaching and Teacher Education, 61, 189-198.

Creswell, J. (2007). Qualitative Inquiry \& Research Design: Choosing Among Five Approaches (2nd Ed.). London: Sage Publications.

Creswell, J., \& Plano Clark, V. (2011). Designing and Conducting Mixed Methods Research (2nd Ed.). London: Sage Publications.

Dadds, M. (2014). Continuing Professional Development: nurturing the expert within. Professional Development in Education, 40(1), 9-16.

Darling-Hammond, L. (2010). The flat world and education: How America's commitment to equity will determine our future (1st Ed.). New York, NY: Teachers College Press.

Day, C. (1999). Developing Teachers: The challenges of lifelong learning. London: Falmer.

Day, C., \& Sachs, J. (2004). International handbook on the continuing professional development of teachers. Maidenhead: Open University Press.

Finefter-Rosenbluh, I. (2016). Behind the scenes of reflective practice in professional development: A glance into the ethical predicaments of secondary school teachers. Teaching and Teacher Education, 60, 1-11.

Fraser, C. (2005). Towards a unified model of professional development? School of Education: University of Aberdeen.

Fraser, C., Kennedy, A., Reid, L., \& Mckinney, S. (2007). Teachers' continuing professional development: contested concepts, understandings and models. Journal of In-Service Education, 33(2), 153-169.

Freire, P. (1970). Pedagogy of the oppressed. New York: Herder and Herder.

Freire, P. (1998). Pedagogy of hope: Reliving Pedagogy of the oppressed. New York: Continuum.

Giroux, H. (1988). Teachers as intellectuals: toward a critical pedagogy of learning. USA: Bergin \& Garvey Publishers, Inc. 
Giroux, H. (2013). Neoliberalism's War against Teachers in Dark Times. Cultural Studies $\leftrightarrow$ Critical Methodologies, 13(6), 458-468.

Giroux, H. (2017). Democratic Education under Siege in a Neoliberal Society. In C. Wright-Maley \& T. Davis (Eds.), Teaching for Democracy in an Age of Economic Disparity (pp. 13-24). New York: Routledge Taylor \& Francis Group.

Hargreaves, A. (2003). Teaching in the knowledge society: Education in the Age of Insecurity. New York: Teachers College Press.

Harrison, J. (2011). Professional Learning and the Reflective Practitioner. In S. Dymoke, Reflective Teaching and Learning in the Secondary Schools (pp. 6-46). London: Sage.

Hung, H., \& Yeh, H. (2013). Forming a change environment to encourage professional development through a teacher study group. Teaching and Teacher Education, 36, 153-165. http://dx.doi.org/10.1016/j.tate.2013.07.009.

Ingvarson, L. (1998). Professional development as the pursuit of professional standards. Teaching and Teacher Education, 14(1), 127-140.

Jamieson, S. (2016). Analyse qualitative data. Education for Primary Care, 27(5), 398-402.

Kane, R., \& Warner, D. (1997). Motivating Students to Read (MA Thesis). Saint Xavier University and IRI/Skylight, Illinois- Chicago Suburbs.

Kennedy, A. (2005). Models of Continuing Professional Development: a framework for analysis. Journal of In-Service Education, 31(2), 235-250.

Kershaw, A. (2012). Critical Pedagogy in Criminal Justice Higher Education: A Liberative Paradigm (Online Theses and Dissertations). University of Kentucky, Lexington, Kentucky.

Kincheloe, J. (1991). Teachers as researchers: qualitative inquiry as a path of empowerment. London: Falmer Press.

Kumaravadivelu, B. (2012). Language Teacher Education for a Global Society: A Modular Model for Knowing, Analysing, Recognising, Doing, and Seeing. London: Routledge.

Kuusisaari, H. (2014). Teachers at the zone of proximal development - Collaboration promoting or hindering the development process. Teaching and Teacher Education, 43, 46-57. http://dx.doi.org/10.1016/j.tate.2014.06.001.

Kvale, S. (2009). Interviews: An Introduction to Qualitative Research Interviewing. London: Sage Publications Ltd.

Lee, I. (2011). Teachers as presenters at continuing professional development seminars in the English-as-a-foreign-language context: 'I find it more convincing'. Australian Journal of Teacher Education, 36(2), 30-42.

Lefstein, A., \& Perath, H. (2014). Empowering teacher voices in an education policy discussion: Paradoxes of representation. Teaching and Teacher Education, 38, 33-43. http://dx.doi.org/10.1016/j.tate.2013.11.001.

Moran, M., Bove, C., Brookshire, R., Braga, P., \& Mantovani, S. (2017). Learning from each other: The design and implementation of a cross-cultural research and professional development model in Italian and U.S. toddler classrooms. Teaching and Teacher Education, 63, 1-11.

Mushayikwa, E., \& Lubben, F. (2009). Self-directed professional development - Hope for teachers working in deprived environments?. Teaching and Teacher Education, 25(3), 375-382. http://dx.doi.org/10.1016/j.tate.2008.12.003.

Oolbekkink-Marchand, H., Hadar, L., Smith, K., Helleve, I., \& Ulvik, M. (2017). Teachers' perceived professional space and their agency. Teaching and Teacher Education, 62, 37-46. http://dx.doi.org/10.1016/j.tate.2016.11.005.

Opfer, V., Pedder, D., \& Lavicza, Z. (2011). The role of teachers' orientation to learning in professional development and change: A national study of teachers in England. Teaching and Teacher Education, 27(2), 443-453. 
Pai, Y. (1990). Cultural Pluralism, Democracy and multicultural Education. In B. Cassara, Adult Education in a Multicultural Society (pp. 11-27). London: Routledge.

Peercy, M., \& Troyan, F. (2017). Making transparent the challenges of developing a practice-based pedagogy of teacher education. Teaching and Teacher Education, 61, 26-36. http://dx.doi.org/10.1016/j.tate.2016.10.005.

Pollard, A., Anderson, J., Maddock, M., Swaffield, S., Warin, J., \& Warwick, P. (2008). Reflective teaching (3rd Ed.). London: Continuum International Publishing Group.

Punch, K. (2014). Introduction to Social Research: Quantitative and Qualitative Approaches (3rd Ed.). London: Sage Publications.

Reilly, E., \& Literat, I. (2012). Designing with Teachers: Participatory Approaches to Professional Development in Education. USC Annenberg Innov. Lab.

Richards, J., \& Lockhart, C. (1996). Reflective teaching in second language classrooms. Cambridge: Cambridge University Press.

Schon, D. (1987). Educating the reflective practitioner. San Francisco: Jossey-Bass.

Taylor, L. (2017). How teachers become teacher researchers: Narrative as a tool for teacher identity construction. Teaching and Teacher Education, 61, 16-25. http://dx. doi.org/10.1016/j.tate.2016.09.008.

Troudi, S. (2015). Critical research in TESOL and Language Education. In C. Coombe \& J. Dean (Eds.), The Cambridge Guide to Research in Language Teaching and Learning (pp. 89-98). Cambridge: Cambridge University Press.

Vangrieken, K., Meredith, C., Packer, T., \& Kyndt, E. (2017). Teacher communities as a context for professional development: A systematic review. Teaching and Teacher Education, 61, 47-59. doi.org/10.1016/j.tate.2016.10.001.

Vrikki, M., Warwick, P., Vermunt, J., Mercer, N., \& Van Halem, N. (2017). Teacher learning in the context of Lesson Study: A video-based analysis of teacher discussions. Teaching and Teacher Education, 61, 211-224.

Vygotsky, L. (1978). Mind in Society. The Development of Higher Psychological Processes. Cambridge, MA: Harvard University Press.

Wai Yan, W. (2011). Teachers' Perceptions and Experiences of Continuing Professional Development (CPD): Opportunities and Needs in Hong Kong Primary Schools $(\mathrm{PhD}$ Thesis). University of Nottingham, United Kingdom.

Witte, T., \& Jansen, E. (2016). Students' voice on literature teacher excellence. Towards a teacher-organized model of continuing professional development. Teaching and Teacher Education, 56, 162-172.

Wyatt, M. (2011). Teachers researching their own practice. ELT Journal, 65(4), 417-425. http://dx.doi.org/10.1093/elt/ccq074. 
